\title{
Bacterial and fungal flora of seagull droppings in Jersey
}

\author{
JOHN CRAGG AND YVONNE M. CLAYTON \\ From the Department of Pathology, General Hospital, Jersey, Channel Isles, and the Department of \\ Medical Mycology, The Institute of Dermatology, St John's Hospital for Diseases of the Skin, London
}

SYNOPSIS In Jersey 166 fresh and 122 dried seagull droppings were obtained and studied locally and in London for the presence of bacteria and fungi of potentially pathogenic nature. There were no salmonella or shigella bacteria isolated from the two groups but there was a high proportion of Candida albicans obtained from the fresh material $(21.7 \%)$ and only $1.6 \%$ from the dry faeces. Cryptococcus neoformans and Histoplasma capsulatum were not found in either the dry or fresh droppings. The normal bacterial and fungal flora of the seagull was established and it is considered that the C. albicans in fresh gull droppings would not materially increase albicans infections in man.

The association between pigeon droppings and the isolation of Cr. neoformans was first described by Emmons (1955). This yeast has been isolated from pigeon droppings in London by Randhawa, Clayton, and Riddell (1965) and by Partridge and Winner (1965). The relationship of $H$. capsulatum to avian habits has been reviewed by Ajello (1964) and the organism has been reported in droppings from chickens, pigeons, and bats (Lehan and Furcolow, 1957; Stoker, 1964). Seagulls are common birds in coastal and island areas, and although yeast species and trematodes in the gull have been studied (Kawakita and van Uden, 1965; Harris, 1964), not much attention has been paid to these birds as possible sources of infection to man; the normal bacterial and fungal flora of the seagull also seems to be obscure. The commonest resident species of gull in Jersey is the herring gull (Larus argentatus) but large numbers of the black-headed gull (Larus ridibundus) also winter in the island. The great black-backed gull (Larus marinus) and the lesser black-backed gull (Larus fuscus) both nest sparingly on the north coast and are sometimes seen elsewhere in the island. Specimens of droppings were collected from around the hospital and also on the southern and eastern shores of the island; the north coast was not studied. Although the possibility of their droppings having been collected is small, the contribution made by the great black-backed gull and the lesser black-backed gull cannot be excluded altogether.

Received for publication 24 August 1970.

\section{Method}

Throughout all seasons of 1967 and 1968 fresh droppings from seagulls were collected on sterile cotton wool swabs moistened with saline; the dried droppings were obtained in similar manner from areas frequented by seagulls. The colour of the dropping was noted and the swab then plated onto $5 \%$ horse blood agar containing $0.05 \mathrm{~g} / 1$ chloramphenicol, McConkey agar, and $1 \%$ glucose agar in addition to Sabouraud's glucose medium with $0.05 \mathrm{~g} / 1$ chloramphenicol. The plates were incubated at $37^{\circ} \mathrm{C}$ with the exception of the Sabouraud's medium which was grown at room temperature. No anaerobic cultures of the droppings were made. A smear was prepared from each dropping and stained by the Gram method. Production of chlamydospores on corn-meal agar and germ-tube formation in one and a half hours when inoculated into human serum were used as confirmatory tests for Candida albicans. The blood agar and glucose agar plates were kept for two weeks and the fungi growing on the Sabouraud's cultures were retained indefinitely by means of subculture until the fungus had been identified.

\section{Results}

\section{BACTERIOLOGY}

Fresh droppings

The commonest colours of these droppings were brown, white, yellow, grey, and green. Polymorphs 
were present in moderate numbers in three droppings and in small numbers in 10 specimens; in no case was there frank mucopus or red blood cells. The commonest bacteria in the faecal flora were Escherichia coli, followed by Aerobacter aerogenes, Proteus sp, paracolon organisms including Hafnia alvei and also Alkaligenes faecalis. Other bacteria found with regularity were members of the genus Lactobacillus, Bacillus subtilis and Bacillus cereus, Staphylococcus aureus and albus, and also Streptococcus faecalis.

\section{Dry droppings}

The number and types of bacteria were greatly reduced as compared with those of fresh droppings. The colours were white, brown, yellow, and green. Polymorphs were present in scanty numbers only in eight droppings and there was no mucopus. The commonest bacteria were $E$. coli; the other Gramnegative bacilli mentioned in the fresh droppings were present but in reduced numbers. There were no salmonella or shigella pathogens.

\section{MYCOLOGY}

Fresh droppings

Candida-like cells could be seen in the majority of the Gram smears; C. albicans was isolated from 36 of the 166 droppings examined $(21 \cdot 7 \%)$. Other yeasts in order of frequency of isolation (the number of isolations appearing in brackets) were $C$. guilliermondii (7), Rhodotorula sp. (4), C. krusei (2), Trichosporon sp (2), and Torulopsis glabrata (1). The filamentous fungi isolated included species of Geotrichum, Pullularia, Neurospora, Penicillium, Aspergillus, Rhizopus, Scopulariopsis, and Fusarium. Neither $C r$. neoformans nor $H$. capsulatum strains were isolated.

\section{Dry droppings}

Only in two of the droppings was $C$. albicans isolated out of a total of 122 studied $(1.6 \%)$. A similar flora to that of the fresh droppings was seen and neither $C r$. neoformans nor $\boldsymbol{H}$. capsulatum were found. The yeasts isolated were $C$. parapsilosis (3), C. krusei (1), C. melibiosi (1), C. zeylanoides (1), Cr. lactavivorous (1), and Torulopsis famata (1). Sporotrichum species were the most common filamentous fungi grown. Epicoccum, Phoma, Aspergillus, Fusarium, and Streptomyces species were also found.

\section{Discussion}

The absence of salmonella and shigella from the fresh and dry droppings, in spite of the scavenging habits of herring gulls, suggests that the foreshore is clean and that sewage disposal is adequate. The normal bacterial flora of seagulls consists of $E \overrightarrow{\overline{\overrightarrow{\hat{\phi}}}}$ coli and other members of the Enterobacteriaecae Bacillus subtilis and B. cereus, Staphylococcus aureus and S. albus, Streptococcus faecalis, and members of the genus Lactobacillus.

Large numbers of seagull droppings were screene $\stackrel{\Phi}{\rho}$ for the presence of $C r$. neoformans and $H$. capsus latum; both these pathogens were absent. Partridgeb and Winner (1965) found that $C r$. neoformans could be isolated from pigeon droppings in the warmefw months but not in winter. It should be pointed out that the present study of seagull droppings extendedP throughout the year and was not confined to summer There is a high natural salt content of all masonry around the shore and this might be a potentia inhibiting agent. It is well known that this yeast is more readily recovered from specimens of organic material collected from sheltered sites, inside and outside of buildings, not in direct contact witw organically enriched soil (Denton and di Salvo, 1968).

The absence of $H$. capsulatum was not surprising. Moisture and temperature are critical for the survival of this fungus (Goodman and Larsh, 1967) The geographical distribution of isolations of this fungus from soil includes the USA, Mexico Panama, South America, Africa, and Malay $\underset{2}{\mathbb{2}}$ (Ajello, 1964). It has not yet been isolated from British soil.

The isolation of C. albicans from $21.7 \%$ of fresh droppings suggests that gull faecal material is $\overrightarrow{0}$ good growth medium for some fungi and also. bacteria. C. albicans is found as a saprophyte in the human bowel and this incidence increases with the use of broad-spectrum antibiotics (Seelig, 1966) the $C$. albicans found in seagulls is also mose probably a saprophyte.

Whilst the incidence of candidiasis has increased in recent years (Seelig, 1966) it is most unlikely thap the presence of this yeast in seagull droppings care materially add to human carriage rate in coastals areas. To be transmissible the yeast would have to be present in dried droppings as is the case with $C r$ neoformans in the excreta of pigeons. In fact, $C \omega$ albicans is present only in a small number of driec droppings and any transmission from fresh faeces would have to be by direct contact and this io unlikely. It is also improbable that contamination ${ }^{+}$ of fresh water reservoirs in coastal areas by fresh seagull droppings would be a major problem? particularly in view of the low water temperatures of the northern latitudes (Taysi and van Uden, 1964) $\$$ this might be a problem, however, in warmee countries. 
We should like to thank Mr A. V. Andrews and Mrs C. Beveridge of the Bacteriology Department, Jersey General Hospital, for their valuable technical assistance, and Mrs Frances Le Sueur of Jersey, Dr J. J. M. Flegg of the British Trust for Ornithology, and Dr M. P. Harris of the Edward Grey Institute, Oxford, for helpful advice.

\section{References}

Ajello, L. (1964). Relationship of Histoplasma capsulatum to avian habitats. Publ. Hlth Rep. (Wash.), 79, 266-270.

Denton, J. F., and Salvo, A. F. di (1968). The prevalence of Cryptococcus neoformans in various natural habitats. Sabouraudia, 6, 213-217.

Emmons, C. W. (1955). Saprophytic sources of Cryptococcus neoformans associated with the pigeon (Columba livia). Amer. J. Hyg., 62, 227-232.
Goodman, N. L., and Larsh, H. W. (1967). Environmental factors and growth of Histoplasma capsulatum in soil. Mycopathologia (Den Haag), 33, 145-156.

Harris, M. P. (1964). The incidence of some species of trematoda in three species of Larus gulls in Wales. Mycopathologia (Den Haag), 106, 532-536.

Kawakita, S., and Uden, N. van. (1965). Occurrence and population densities of yeast species in the digestive tracts of gulls and terns. J. gen. Microbiol., 39, 125-129.

Lehan, P. H., and Furcolow, M. L. (1967). Epidemic histoplasmosis. J. chron. Dis., 5, 489-503.

Partridge, B. M., and Winner, H. I. (1965). Cryptococcus neoformans in bird droppings in London. Lancet, 1 1060-1061.

Randhawa, H.S., Clayton, Y. M., and Riddell, R. W. (1965). Isolation of Cryptococcus neoformans from pigeon habitats in London. Nature (Lond.), 208, 801.

Seelig, M. S. (1966). The role of antibiotics in the pathogenesis of Candida infections. Amer. J. Med., 40, 887-917.

Stoker, D. J. (1964). Histoplasmosis in Cyprus: Report of two cases. Brit. med. J., 11, 793-795.

Taysi, I., and Van Uden, N. (1964). Occurrence and population densities of yeast species in an esturine-marine area. Limnol. Oceanon., 9, 42-45. 